\title{
Alternative Energies and Undergraduate Research
}

\author{
C. C. Chancey, Editor \\ American Journal of Undergraduate Research \\ University of Northern lowa \\ Cedar Falls, lowa 50614-0150 USA
}

High oil prices this spring are a reminder of the fragile energy economy that now operates world wide. Estimates vary over whether we have passed the peak of oil production, but no one argues over oil as an increasingly scare commodity. Changing weather patterns also are playing havoc with some supposedly renewable energy sources such as hydroelectric power. The US Climate Change Science Program recently issued an assessment that predicts a significantly drier climate for the American west over the next 50 years (see the May 29 press release and the May 27, 2008, final report at ww.climatescience.gov). If this occurs, the

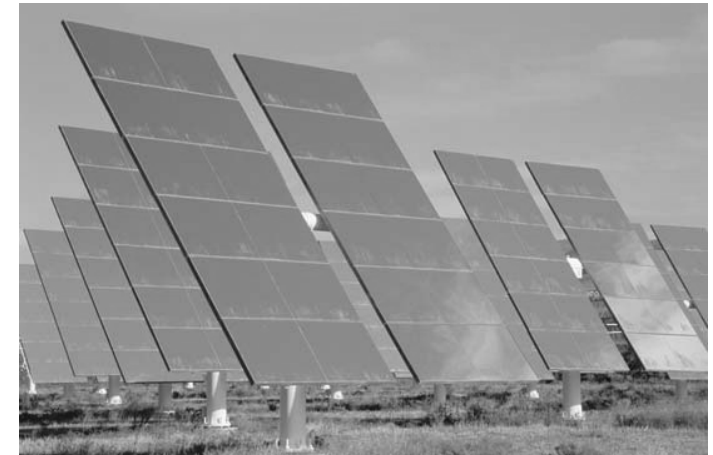

Photovoltaic power plant in the Tabernas desert, Andalusia, Spain.

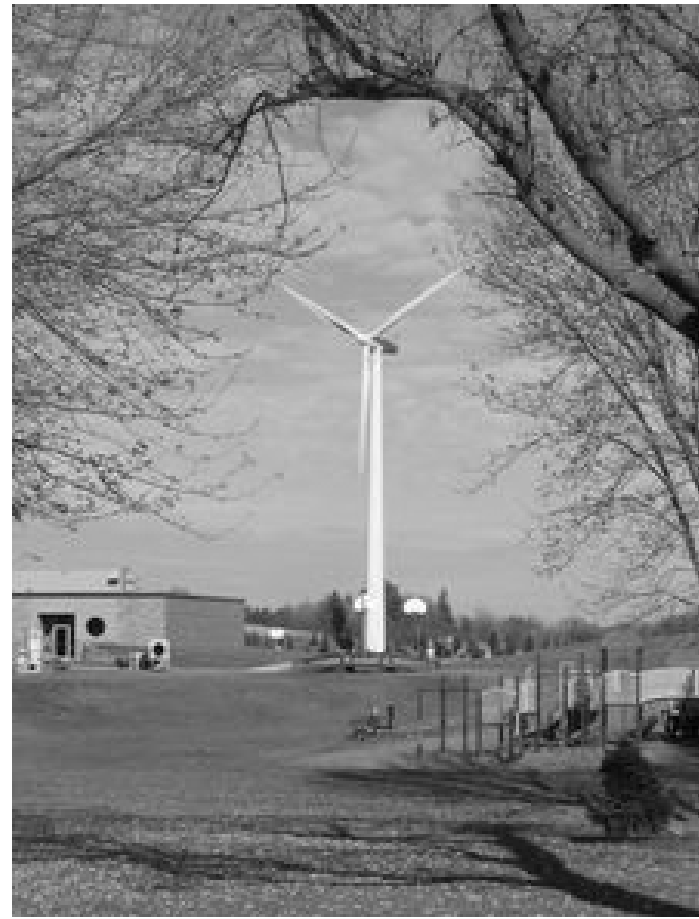

A wind turbine built by MidAmerican Energy as part of its Renewable Advantage Program to power all the rides and grounds of the2007 lowa State Fair. region's hydroelectric generating capacity will be severely reduced, affecting cities from Denver to Los Angeles.

A number of countries, particularly in Europe, have taken steps to develop other energy sources: some depend on nuclear power; some have invested in solar and wind power generation; many have invested in public policies that support energy conservation.

World-wide energy needs in the future will push the envelopes of these technologies even as we seek to engineer new technologies. Part of the challenge will be to develop robust but inexpensive renewable energy technologies that do not require vast infrastructures. The small methane vats of rural India would be a successful current example.

Aspects of meeting these design challenges are well within the range of undergraduate research capabilities. Undergraduates can play a part in meeting an important global need, applying science in a socially responsible way-something all of us can encourage. 